\title{
SOFTWARES LIVRES E GOVERNO: UM FILETE DE ÁGUA NO MOINHO DIGITAL
}

\author{
Marcos Vinicio Chein Feres ${ }^{1}$ \\ Jordan Vinícius de Oliveira ${ }^{2}$
}

\section{Resumo}

A tarefa de investigar a escolha por parte de governos em adotar softwares livres demanda uma análise profunda sobre o cenário do mercado de programas de computador. Através de um método de análise empírica e qualitativa, visa-se aprofundar na compreensão dos caracteres pelos quais se constitui o setor de softwares e elencar os principais problemas a serem enfrentados. O plano teórico adotado é o da luta pelo reconhecimento e o do viver plenamente o direito. A principal constatação é de que a adoção do modelo de open source pelo Governo Federal não é capaz de figurar como fator transformador da realidade do mercado, monopolizada pelas estruturas dos softwares de código-fontefechados.

Palavras-chave: Luta por reconhecimento. Vivendo plenamente a lei. Propriedade Intelectual. Softwares Livres. Código-fonte.

\section{INTRODUÇÃO}

Esta pesquisa objetiva compreender o processo de adoção de softwares livres pelo governo brasileiro e por governos em geral, num panorama mais amplo. Desde 2003, quando o Governo Federal optou por migrar das formas proprietárias de programas de computador - que possuem o código-fonte fechado - até os últimos dados disponíveis, referentes ao ano de 2013, o cenário deste mercado sofreu algumas transformações, contudo não se alterou em termos significativos.

$\underline{\text { A importância desta temática se insere em um contexto de revolução da tecnologia e da informação, no }}$ qual os softwares possuem um papel fundamental para a soberania tecnológica e informacional de um país e seu respectivo governo. Para tanto, basta refletir sobre os enormes avanços da computação e da informática impulsionados pelos programas de computador nos últimos tempos como, por exemplo, o advento da internet e contrabalancear tais evoluções com as estruturas de propriedade intelectual utilizadas para proteger os autores e fomentar a inovação, como os direitos autorais, que permanecem ainda nos moldesclássicos.

${ }^{1}$ Doutor em Direito, Professor Associado da Universidade Federal de Juiz de Fora e Professor do Corpo Permanente do Programa de Pós-Graduação Estrito Senso em Direito e Inovação da Faculdade de Direito da UFJF. Bolsista de Produtividade PQ-2 do CNPq. E-mail: mvchein@gmail.com

${ }^{2}$ Graduando em Direito pela Universidade Federal de Juiz de Fora. Pesquisador PIBIC/CNPq na subárea de Propriedade Intelectual. E-mail: jordanvinicio@gmail.com 
O advento dos softwares livres como opções de mercado, sua concorrência com as formas proprietárias fechadas e a classificação do tipo de medida adotada pelo governo brasileiro, se de caráter intervencionista ou se mera faculdade, são alguns dos aspectos analisados.

Enquanto uma pesquisa empírico-analítica o maior foco se funda na compreensão de como as formas de incentivo e de propriedade intelectual que interagem com os softwares e interferem em seu respectivo mercado no cenário nacional, dando indícios do comportamento global deste setor econômico. Tal análise se baseia ainda em literatura técnica sobre as estruturas do direito autoral para a proteção dos softwares empregadas por governos e nas diretrizes teóricas da filosofia e do direito, respectivamente Axel Honneth e Zenon Bankowski, como marcos interpretativos dos dados analisados. Investigam-se os desdobramentos econômicos e comportamentais das escolhas dos governos por tipos específicos de padrão desoftware.

Inicialmente, no item 2, objetiva-se explicar os planos teóricos e a metodologia adotada, subdividida em três etapas: a elucidação do marco teórico escolhido, a explanação da espécie de análise metodológica empregada bem como dos tipos de dados estudados e, por fim, a realização de inferências.

$\mathrm{O}$ item 3 visa, por meio do estudo bibliográfico indireto, elencar alguns exemplos de governos pelo mundo que adotaram os softwares livres e as principais razões geralmente apontadas por eles para abandonarem as formas fechadas. Investiga-se também neste item quais os motivos apontados possuem fundamentos mais concisos e os que são de construção mais frágil.

No item 4 há uma subdivisão de enfoques entre as razões especificamente alegadas pelo governo brasileiro para a migração ao uso de softwares livres e o panorama do mercado nacional de softwares, por meio da criação de tabelas elaboradas a partir de dados oficiais disponíveis. Portanto, este item é uma contraposição entre as razões levantadas pelo governo brasileiro para a adoção dos softwares livres e o efetivo impacto no setor nacional de programas de computador.

Por fim, busca-se trazer uma síntese dos dados diretos e indiretos que foram coletados e realizar um processo de inferências que se norteia pelos autores jusfilosóficos escolhidos para esta pesquisa.

Em conjunto, estas etapas visam classificar de forma empírica qual o tipo de escolha realizada pelo governo brasileiro dentro dos parâmetros jurídicos e administrativos vigentes: se uma escolha de intervenção de mercado ou se mera opção técnica. Além disso, estabelece-se um relevante retrato do mercado nacional de software e de suas principais nuances e incompletudes, o que pode possibilitar futuras ações visando sua melhoria ou suscitar novos estudos sobre o tema. 


\section{DA FUNDAMENTAÇÃO TEÓRICA E METODOLÓGICA}

Estabelecer uma metodologia rigorosa, sobretudo no âmbito das ciências jurídicas, não é tarefa de fácil realização. Para trazer algum traço de cientificidade à pesquisa em direito, faz-se salutar ir além da opinião jurídica e da mera crítica de legislação e buscar estabelecer uma investigação mais rigorosa e pautada em aspectos não somente dogmáticos, mas também empíricos, constatáveis na realidade cotidiana.

Assim, o caminho metodológico deve visar explicar não somente o que foi feito, mas sobretudo como se deu cada passo até o resultado final, de modo a permitir que critérios científicos irriguem e complementem a seara legal e que seja evidenciado o processo de realização deste estudo.

A visão adotada é a de que o Direito, como ciência social aplicada, não deve se afastar de adotar padrões que permitam a interação com as demais áreas que constroem a observação dos fenômenos sociais. Não deve se fechar apenas em seu próprio vocabulário e formas de produção legal, pois cuida de aspectos multifacetados que afetam a vida em sociedade em geral. Assim, deve adotar e respeitar parâmetros mínimos que permitam seu diálogo e seu crescimento junto a outras óticas.

Nesta toada, a abordagem que aqui se pretende desempenhar funda-se em três pilares, quais sejam: a explanação do marco teórico escolhido, o desenvolvimento da metodologia de análise e o estabelecimento de um processo de inferências - etapas que se desenvolvem a seguir.

\section{Do Marco Teórico}

Primeiramente, o estabelecimento de um contexto teórico faz-se de profunda importância na pesquisa jurídica, uma vez que se escolhe uma ótica basilar para guiar todos os resultados e conclusões desenvolvidos, ou seja, um substrato filosófico e legal que possibilite a melhor compreensão do fenômeno observado. Não se trata de mera escolha técnica do assunto desenvolvido, a saber: a adequação das escolhas governamentais para a adoção ou o incentivo do tipo de software mais cabível, de código fechado ou aberto, para a administração pública.

Nesse sentido, o plano teórico que vem sendo desenvolvido ao longo desta pesquisa científica é o do viver plenamente a lei, de Zenon Bankowski (2008), aliado ao da luta pelo reconhecimento, de Axel Honneth (2003). Estes dois marcos teóricos se complementam na medida em que possibilitam uma abordagem para além da investigação tecnicista da lei por si só e permitem a interação do direito com o campo filosófico.

Para Bankowski (1996;1997; 2008), viver plenamente a lei significa estabelecer uma relação saudável e equilibrada entre dois lados de uma mesma moeda: a lei e o amor. A importância da lei surge para evitar um estado de caos social, enquanto o amor opera não no sentido romântico, mas para combater um estado de burocracia perversa, em que as regras são mais importantes do que os próprios seres humanos. 
Tal relação harmônica entre estes dois componentes permite o que Bankowski chama de "explosões de atos de amor": a evolução dos sistemas normativos em compasso com as transformações sociais, através do questionamento reiterado de uma norma sob o prisma das aspirações que a fizeramsurgir.

Para o objeto em estudo, o software, tal marco teórico é empregado para investigar a necessidade de mudança das estruturas clássicas de proteção da propriedade intelectual diante dos novos tempos, marcados por $\underline{\text { fluxo constantes de informação e tecnologia. Assim, questionar quais as aspirações por detrás das leis revela a }}$ $\underline{\text { matriz deste estudo e se centra no incentivo de governos, como o brasileiro, a um determinado tipo de software, }}$ como o software livre.

Tal viés é complementado pelo outro norte teórico deste artigo, a partir da noção de luta pelo reconhecimento, de Honneth (2003). Esta é uma luta que se desdobra nas células das sociedades das quais os indivíduos fazem parte, não mais se faz na forma arcaica e individualista, de todos contra todos, mas na busca por um processo interdependente de três fases: a da autoconfiança através do amor nas relações internas; do autorrespeito pelo papel do direito nas relações mútuas e da solidariedade para o alcance da estima social, numa perspectiva integrada entre o sujeito e seu meio social.

O encaixe da filosofia de Honneth visa complementar a ótica evolucionista do direito de Bankowski para compreender os desdobramentos sociais do objeto estudado. Entender qual o tipo de software um governo incentiva e quais os fundamentos para tanto requer uma perspectiva que perpasse a tecnicidade, o que justifica a adoção destes marcos teóricos para este tema tão peculiar.

\section{A metodologia utilizada}

A metodologia empregada parte do caminho teórico traçado acima, para se desdobrar numa forma de análise empírica e qualitativa de conteúdo. Assim, estabelece-se o tipo de conteúdo analisado, direto e indireto e a forma de análise empregada, que conforme Babbie (2007), é uma análise qualitativa por traços de significação (unobtrusive research).

Esta forma de análise se desenvolve pelo levantamento de todo o conteúdo publicamente disponível $\underline{\text { sobre o tema investigado, qual seja, a relação entre governos e software, estabelecendo assim hipóteses iniciais. }}$ Destas hipóteses ocorre a contraposição entre as informações iniciais e os dados coletados sobre o assunto, tendo em consideração o marco teórico adotado, para por fim, construir um panorama de questionamentos no qual se tem a realidade fática e o ideal normativo contrastados, gerando uma reestruturação e um redimensionamento do objeto estudado (BABBIE, 2007). 
No que tange ao tipo de conteúdo analisado, este possui natureza indireta e também direta. O conteúdo direto se encontra em relatórios especializados da $\mathrm{ABES}^{3}$ sobre mercado de programas de computador e a utilização de softwares livres no mercado nacional. Também se realiza uma análise documental direta através do estudo do Guia Livre $(2005)^{4}$, lançado pelo Governo.

O conteúdo indireto é de cunho bibliográfico e documental disponível, como artigos internacionais com diferentes análises sobre este tema. Enquanto o marco teórico permite interpretar jusfilosoficamente as informações colhidas, este conteúdo indireto permite a compreensão técnica do temainvestigado.

O terceiro e último passo metodológico a ser esclarecido se apresenta pela realização de um sistema válido de inferências. Estas se dividem em descritivas e causais, nos moldes da análise proposta por Epstein e King (2013), e visam a elucidação do processo utilizado. As inferências descritivas surgem pela utilização de fatos conhecidos para a compreensão de fenômenos contidos num assunto de escopo ainda maior, inicialmente desconhecido. No caso em questão, utiliza-se o contexto legislativo e governamental brasileiro para compreender, de modo geral, a utilização de softwares livres por governos no mundo todo, respeitando-se as especificidades de cada caso e seus limites.

As inferências são também causais, ao ponto em que empregam o marco de incentivos governamentais para utilização do tipo livre de software, o que se chama de "variável principal", para compreender suas influências no mercado e eventuais benefícios ou prejuízos à sociedade como um todo, ou seja, sua repercussão, o que se pode chamar de "variável dependente"(EPSTEIN e KING, 2013).

Deste modo, com o caminho metodológico já explicitado, segue-se à discussão e análise de dados acerca do tema estudado, como próxima etapa desta pesquisa. Antes, destaca-se ainda o alto grau de verossimilhança das constatações aqui realizadas, sem que haja nível absoluto de certeza o que, como abordado por Epstein e King (2013), não se desdobra de forma alguma em invalidade ou descredenciamento da pesquisa, mas sim em buscar a evidência de todo o processo de análise realizado. [Comentário: Menor desenvolvimento do marco teórico e da metodologia, como sugerido pelo Avaliador B. Para que o texto não ficasse aquém do limite mínimo de 20 páginas outros trechos foram acrescidos ao longo do mesmo, em negrito. Também estão em negrito as correções observadas pelo Avaliador A no arquivo disponibilizado]

\section{GOVERNOS E SOFTWARES LIVRES: ALGUMAS EXPERIENCIAS}

A escolha sobre qual o tipo de software adotar, se de padrão livre - onde o código-fonte é compartilhado e há a preocupação com a liberdade do usuário e desenvolvedor -, ou de padrão fechado - onde o código-fonte é

\footnotetext{
${ }^{3}$ Associação Brasileira das Empresas de Software. Website oficial: <http://www.abessoftware.com.br>.

${ }^{4}$ Documento lançado pelo Governo Federal referência para o processo de migração de suas instâncias para os softwares livres.
} 
restrito aos seus proprietários (GUIA LIVRE, 2005) -, é assunto que naturalmente suscita embates e discussões nos diversos meios acadêmicos. Quando este tema chega à seara da administração pública, isto é, quando se trata de qual o tipo de padrão de software que governos e entidades relacionadas devem adotar, ganha conotações ainda mais complexas.

Em sua análise sobre as escolhas de governos pelos softwares livres, Casson e Ryan (2006) apontam que a migração dos softwares proprietários para esta nova opção ocorreu visando dois pontos centrais correlatos, quais sejam: prevenir a ocorrência do chamado efeito lock-in, em que o consumidor fica literalmente preso ou dependente de um tipo de software e, assim, conceder a liberdade de escolha dentro de um mercado competitivo.

A primeira constatação se dá pelo fato de o setor de informática e de software estar sujeito à ocorrência de rápidas evoluções e consequentes mudanças de padrões. Diante desta necessidade, caso o governo usuário do serviço fique refém de um único fornecedor proprietário, assume o risco de que aquele dado programa utilizado caia em obsolescência no mercado e de que fique à deriva com os altos custos para uma eventual troca de um programa ultrapassado e alheio a novas tecnologias, para outros mais populares, que possam surgir. A segunda constatação se dá pela simples faculdade de o governo poder trocar de empresa fornecedora de software quando bem entender e, dessa forma, manter a competitividade no mercado e nos preços praticados, prevenindo a obsolescência de seus programas (CASSON; RYAN, 2006).

Evans e Reddy (2002) citam que diversas são as justificativas utilizadas pelos governos que adotam o padrão de software livre, dentre as quais cabe breve síntese de motivos, como: o fato de o código-fonte aberto estar menos sujeito a ataques de vírus e de ter maior segurança de informações; o fato de apresentar maior economicidade, com menores custos; a independência para poder adotar e migrar para qualquer outro tipo de software, se necessário; o incentivo à inovação, à competição, ao mercado local e, também, pela filosofia da forma livre de utilização em suas motivações ideológicas, em que o conhecimento écompartilhado.

No entanto, apontam que estes argumentos trazidos não prosperam sempre, como pelo fato de a inovação ser pouca, pois os softwares livres apresentam geralmente alternativas já criadas pelos softwares proprietários. Além disso, os custos não são necessariamente sempre menores, pois embora o software livre seja, na maioria das vezes mais barato, ele é incorporado com gastos de desenvolvimento, suporte, treinamento ou mesmo ajustes que se tornam volumosos ao termo final do contrato (EVANS; REDDY,2002).

Por fim, os autores asseveram que os softwares livres possuem vantagens, como o benefício compartilhado à sociedade, a correção mais ágil de defeitos e a maior proteção à privacidade, mas também contrapontos, como poucos incentivos financeiros e maior incompatibilidade entre múltiplos programas proprietários. 
Os softwares proprietários fechados, por sua vez, têm como atributos positivos a compatibilidade de seus programas, a boa transição que ocorre entre atualizações de suas versões de software e o maior controle deste programa, que é centralizado em um único desenvolvedor. Como pontos negativos, os autores destacam os defeitos que só podem ser corrigidos pelos proprietários, haja vista a restrição do código-fonte e o fato deste tipo de software possuir pouca possibilidade de se adaptar às necessidades de cada cliente, o chamado processo de customização. Apontam, destarte, que a decisão por um modelo proprietário ou aberto de programa de computador por governos deve ser feita conforme as especificidades e necessidades concretas de cada caso (EVANS; REDDY,2002).

Quanto aos casos de adoção de software livre citam-se dois exemplos variados trabalhados por Casson e Ryan (2006): o do governo da cidade de Munique, na Alemanha e o da administração de Massachussets, nos Estados Unidos. No caso de Munique, quando a Microsoft anunciou o fim de suporte ao servidor NT, que propiciava o ambiente de rede do Windows 95 e também do próprio sistema operacional MT, o governo local optou por migrar para o Suse Linux ao invés do Windows XP, dados os gastos e as futuras trocas que seriam ainda mais trabalhosas e evitando assim o efeito "lock-in". Em 2005, a cidade alemã optou por outra versão do Linux, o Linux Debian, num novo processo de troca. Este episódio demonstrou a incipiência do sistema Linux, ainda carente de maior amadurecimento e foi um caso paradigmático por ter sido um dos pioneiros no processo de independência dos governos quanto aos programas de computador proprietários.

Quanto a Massachussets, também visando evitar o efeito "lock-in" e a aquisição de ferramentas de processamento de dados muito caras, o governo não optou por uma espécie particular de software, mas estabeleceu um padrão a ser seguido, tanto por desenvolvedores de software aberto quanto para os de software fechado que quisessem concorrer ao fornecimento tecnológico das instâncias administrativas. Exigiu-se como requisito o formato chamado de "Open Document" para as entidades governamentais, o que propiciou a adoção tanto de modelos livres como a adaptação da Microsoft, que submeteu sua versão de suíte de documentos com padrões abertos, o XML Open Microsoft(CASSON; RYAN, 2006).

\section{O CONTEXTO BRASILEIRO: EXERCÍCIO DE LIVRE ESCOLHA OU INTERVENÇÃO INDEVIDA NO MERCADO DE SOFTWARES?}

Frente a todo o exposto até aqui, cabe agora enfrentar a questão basilar que guiou toda esta pesquisa. Sabendo-se que o governo brasileiro reforçou a escolha por softwares livres em sua administração, seria esta ação classificável como mera faculdade de escolha diante do mercado, ou seria uma típica intervenção indevida nos rumos da ordem econômica dos softwares, prejudicando empresas proprietárias? Nesse contexto, são ressaltadas a análise dos motivos apontados pelo governo brasileiro para a adoção de softwares livres e a análise 
mercadológica pautada no ambiente dos programas de computador para, por fim, realizar inferências dentro das matrizes teóricas que guiam este estudo.

\section{A ascensão do software livre em escala governamental}

No âmbito da Administração Pública Federal, a implementação dos softwares livres se deu de forma significativa a partir do Decreto de 29 de Outubro de $2003^{5}$, que instituiu os Comitês Técnicos, de modo a orientar e a planejar a adoção deste tipo de software no âmbitofederal.

Esta iniciativa do governo brasileiro visava, primeiramente, o processo de migração para os softwares livres no âmbito de órgãos da administração pública federal e, posteriormente, o desenvolvimento nacional da indústria de software em suas particularidades. Segundo o Guia Livre (BRASIL, 2005) ${ }^{6}$, um software livre pode assim ser caracterizado:

Software disponibilizado, gratuito ou comercializado, com as premissas de liberdade de instalação; plena utilização; acesso ao código-fonte; possibilidade de modificações/aperfeiçoamentos para necessidades específicas; distribuição da forma original ou modificada, com ou sem custos (BRASIL,2005).

Assim, no software livre a preocupação principal é com o fruir da tecnologia e do conhecimento utilizados, de forma a trazer para a sociedade da informação a soberania de conhecimento, não disponível nos softwares proprietários fechados.

Dentre as razões listadas pelo governo brasileiro para a escolha pelo software livre encontram-se: a busca por padrões abertos para o Governo Eletrônico, demandas por segurança, independência tecnológica, auditabilidade dos sistemas, desenvolvimento da indústria de softwares local, a fuga das alterações bruscas dos softwares fechados, como o fim de suporte e a mudança de todos os programas e a superação da dependência de um único fornecedor. O documento ainda cita os princípios jurídicos da Impessoalidade, Eficiência e Razoabilidade no âmbito da administração pública (GUIA LIVRE, 2005, capítulo2).

Quanto às razões jurídicas, o Guia Livre (GUIA LIVRE, 2005, capítulo 3) aponta principalmente que objetiva contratar a melhor forma de software para o cidadão brasileiro, uma vez que, com os softwares livres, o país e todos os interessados são contemplados pela distribuição conjunta de informações que existem no códigofonte de um programa, visando à soberania tecnológica nacional.

O documento aponta ainda que não se busca dar preferência a um tipo de programa ou a uma categoria de empresa, mas sim legitimar um sistema democrático, onde o acesso do cidadão ao código-fonte do programa

\footnotetext{
${ }^{5}$ Art. $1^{\circ}$ Ficam instituídos Comitês Técnicos, no âmbito do Comitê Executivo do Governo Eletrônico, criado pelo Decreto de 18 de outubro de 2000, com a finalidade de coordenar e articular o planejamento e a implementação de projetos e ações nas respectivas áreas de competência, com as seguintesdenominações: I - Implementação do Software Livre; (BRASIL, 2003).

${ }^{6}$ Manual elaborado em 2005 que visa esclarecer o processo de migração para o software livre e que contou com colaboração interinstitucional, inclusive com seis audiências públicas e uma consulta pública pela internet.
} 


\section{Quaestio Iuris}

utilizado pelo governo e a possibilidade do uso das informações nele contidas propicia o desenvolvimento da economia e da sociedade em que se vive.

Para além das razões apontadas pelo governo para o processo de migração, é salutar desenvolver uma investigação sobre o panorama concreto do mercado de softwares e os respectivos impactos desta política, já que decorridos alguns anos desde esta mudança, etapa à qual se procede.

\section{O cenário nacional do mercado de softwares}

Dos motivos explicitados por outros governos na adoção de softwares livres e também pelo que foi exposto pelo governo brasileiro, dentro das suas especificidades, entender o real encaixe do contexto que circunda o mercado nacional de programas de computador permite a confirmação e a desconstituição de algumas das razões elencadas para o processo de migração para os softwares livres.

A Tabela $\mathrm{A}^{7}$ foi construída levando em consideração apenas os dados do mercado brasileiro de softwares, sem considerar o setor de serviços, visando apurar os indicadores de desenvolvimento deste tipo de tecnologia em âmbito nacional.

Como os dados são contínuos, com relatórios pormenorizados desde o ano de 2005 até o ano de 2014 , entende-se que não há prejuízos à pesquisa por se limitar a esta fonte justamente pela sua importância e alcance temporal, que acompanha o mercado durante este interregno de dezanos.

Ademais, pela etapa de coleta de dados evidenciou-se que os relatórios da ABES são, em âmbito nacional, os únicos que se dedicam a catalogar informações detalhadas sobre o mercado de softwares, bem como $\underline{\text { sobre o volume de softwares proprietários e livres e o perfil de clientes de cada um destes tipos de programa de }}$ computador.

\begin{tabular}{|r|c|c|c|}
\hline \multicolumn{3}{|c|}{ TABELA A - PANORAMA DO MERCADO NACIONAL DESOFTWARES } \\
\hline ANO & $\begin{array}{c}\text { Volume Total de Mercado } \\
\text { (em US\$) }\end{array}$ & $\begin{array}{c}\text { Participação no Mercado } \\
\text { Mundial }\end{array}$ & $\begin{array}{c}\text { Percentagem de Programas } \\
\text { Desenvolvidos no Exterior }\end{array}$ \\
\hline 2004 & 2,36 Bilhões & $1,1 \%$ & $73 \%$ \\
\hline 2005 & 2,72 Bilhões & $1,2 \%$ & $71 \%$ \\
\hline 2006 & 3,26 Bilhões & $1,3 \%$ & $67,5 \%$ \\
\hline 2007 & 4,19 Bilhões & $1,6 \%$ & $66,4 \%$ \\
\hline 2008 & 5,07 Bilhões & $1,68 \%$ & $67,5 \%$ \\
\hline 2009 & 5,452 Bilhões & $1,69 \%$ & $71 \%$ \\
\hline 2010 & 5,51 Bilhões & $1,8 \%$ & $79 \%$ \\
\hline 2011 & 6,30 Bilhões & $1,1 \%$ & $78 \%$ \\
\hline
\end{tabular}

\footnotetext{
${ }^{7}$ Tabela elaborada a partir da coleta de dados disponibilizados pela Associação Brasileira das Empresas de Softwares (ABES) em seus relatórios "Mercado Brasileiro de Software - Panoramas e Tendências" nas versões anuais de 2005 a 2014. Cada relatório se refere aos dados recolhidos ao longo do anoanterior.
} 


\begin{tabular}{|c|c|c|c|}
\hline 2012 & 9,668 Bilhões & $2,4 \%$ & $77 \%$ \\
\hline 2013 & 10,945 Bilhões & $2,8 \%$ & $76,7 \%$ \\
\hline
\end{tabular}

Os dados constantes nesta tabela demonstram que, embora haja crescimento significativo do mercado de softwares, de um volume inicial de mais de dois bilhões de dólares em 2004 para um montante quase cinco vezes maior ao fim de 2013, ainda é tímida a representatividade do mercado nacional quando comparada frente ao mercado global de programas de computador, de apenas de 2,8\% no ano de 2013.

Ponto relevante se refere justamente ao desenvolvimento de softwares. Desde 2004 até o ano de 2013, há forte caracterização de uma dependência externa para a criação e desenvolvimento destes programas. Conforme demonstram dados do último ano disponível, cerca de três em cada quatro programas desenvolvidos para o mercado brasileiro são oriundos do exterior.

Estes aspectos relatam que a busca pela independência tecnológica na produção de softwares é uma tarefa árdua e ainda de difícil implantação. Para um país do porte territorial e populacional do Brasil, malgrado os esforços do governo federal, ainda há carência no estímulo à formação e aprimoramento da indústria nacional de programas de computador.

Por sua vez, a Tabela $B^{8}$ passa a analisar o mercado de softwares livres, com dois principais subgrupos: um comparativo entre o mercado de "Open Source" e o de softwares proprietários fechados - "Volume Total de Mercado de Software e Serviços" - e um quadro geral sobre a expressividade dos softwares livres - "Demanda por Software Livre".

O primeiro subgrupo elenca os volumes totais dos mercados de software livre e software proprietário no âmbito nacional, no mesmo espaço de tempo, permitindo uma comparação direta entre ambos. Já o outro subgrupo visa estabelecer um panorama geral do mercado brasileiro de softwares livres, sendo elencados o seu principal investidor, constatado como o Governo Federal, os volumes totais expressos em dólares e a proporção destes montantes.

\begin{tabular}{|c|c|c|c|c|c|}
\hline \multicolumn{6}{|c|}{ TABELA B - SITUAÇÃO DO MERCADO DE OPEN SOURCE } \\
\hline \multirow{4}{*}{ ANO } & \multicolumn{5}{|c|}{ ÍNDICES } \\
\hline & \multirow{2}{*}{\multicolumn{2}{|c|}{$\begin{array}{l}\text { Volume Total de Mercado de } \\
\text { Softwares e Serviços (US\$) }\end{array}$}} & \multicolumn{3}{|c|}{ Demanda por Software Livre } \\
\hline & & & \multirow[b]{2}{*}{$\begin{array}{l}\text { Maior Cliente de } \\
\text { Software Livre }\end{array}$} & \multirow{2}{*}{$\begin{array}{l}\text { Volume de } \\
\text { Investimento } \\
\text { (US\$) }\end{array}$} & \multirow[b]{2}{*}{$\begin{array}{l}\text { Percentagem Total } \\
\text { de Investimento }\end{array}$} \\
\hline & $\begin{array}{l}\text { Softwares } \\
\text { Proprietários }\end{array}$ & $\begin{array}{c}\text { Softwares } \\
\text { Livres }\end{array}$ & & & \\
\hline 2010 & $19.04 \mathrm{mi}$ & $563 \mathrm{mi}$ & Governo & $375,2 \mathrm{mi}$ & $66 \%$ \\
\hline 2011 & $21.440 \mathrm{mi}$ & $787 \mathrm{mi}$ & Governo & $535,2 \mathrm{mi}$ & $68 \%$ \\
\hline 2012 & $27.178 \mathrm{mi}$ & $1.033 \mathrm{mi}$ & Governo & $733,3 \mathrm{mi}$ & $71 \%$ \\
\hline 2013 & $25.948 \mathrm{mi}$ & $1.192 \mathrm{mi}$ & Governo & $811,9 \mathrm{mi}$ & $68 \%$ \\
\hline
\end{tabular}

\footnotetext{
${ }^{8}$ Tabela elaborada a partir da coleta de dados disponibilizados pela Associação Brasileira das Empresas de Softwares (ABES) em seus relatórios "Mercado Brasileiro de Software - Panoramas e Tendências". As versões dos relatórios da ABES que passam a tratar do mercado de software livre são as de 2011 a 2014, razão pela qual estes anos foram escolhidos e estão retratados nesta tabela B. Cada relatório se refere aos dados recolhidos ao longo do ano anterior.
} 
Nesta tabela foi considerado o agregado de desenvolvimento de softwares e de serviços, visto que o mercado de softwares livres engloba principalmente o oferecimento de serviços adicionais

Desta segunda leva de dados pode-se extrair alguns demonstrativos significativos sobre o verdadeiro desequilíbrio entre os softwares livres e fechados, em termos de mercado nacional. Isto decorre de anos de consolidação e monopólio das grandes corporações neste território e da adoção quase automática de formas fechadas de softwares.

Aqui, através dos números relativos ao crescimento de cada mercado, pode-se constatar o chamado efeito lock-in, em que o usuário e o mercado em geral ficam aprisionados e dependentes de uma forma de

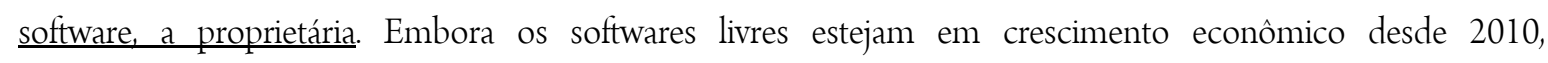
ultrapassando o volume de um bilhão de dólares em 2013, tal ascensão da mesma forma não é significativa diante do mercado proprietário, cerca de vinte e uma vezes maior em termos de volume financeiro.

Em contrapartida, na seara dos softwares livres, faz-se notar o impacto dos investimentos do Governo Federal nas suas instâncias da administração pública, sendo este o maior cliente das formas livres de programas de computador e de forma expressiva em todos os anos analisados.

O montante total de investimentos do governo no setor mais do que duplicou, de cerca de 375 milhões de dólares em 2010 para mais de 800 milhões de dólares em 2013 e o campo "Percentagem Total de Investimento" demonstra que, de todo o volume do mercado de softwares livres, o Governo Federal é responsável por parcelas consideráveis que já chegaram a expressar mais de 70\% dos investimentos neste mercado, como no ano de 2012.

Apontados estes indicadores e feitas estas análises prévias, o último e mais importante estágio desta pesquisa se realiza em seguida, com a discussão destes dados frente ao marco teórico escolhido e a partir de todo o exposto até aqui, para tentar classificar o tipo de escolha de que se valeu a administração pública brasileira na adoção de softwares livres e seus respectivos desdobramentos.

\section{INFERENCIAS E ALGUMAS CONCLUSÕES PRELIMINARES}

Dando sequência aos passos metodológicos adotados, esta derradeira etapa se valerá de inferências descritivas e causais (Epstein e King, 2013), que permitem utilizar todos os dados coletados para compreender o fenômeno da escolha da administração pública por um tipo desoftware.

Inicialmente, de acordo com os dados da Tabela A, constatam-se dois pontos centrais: que o mercado nacional de softwares possui suas potencialidades e que este ainda se encontra extremamente dependente de nuances externas. 
Por meio de um processo de inferências descritivo, em que se utilizam os dados obtidos para chegar ao entendimento de um assunto ainda desconhecido, e também causal, em que se utiliza o fenômeno das adoções de parâmetros de softwares livres na alçada da administração pública e seu consequente impacto no mercado e na comunidade (Epstein e King, 2013), afirma-se que os esforços do governo brasileiro em promover os softwares livres são ainda insuficientes para atingir os objetivos inicialmente visados: de soberania tecnológica e independência externa.

Conforme a teoria da Luta pelo Reconhecimento (HONNETH, 2003), o plano social integrado só passa a adquirir sua plenitude, ou a caminhar nessa direção, a partir do ponto em que cada indivíduo integrante desse quadro institucional possuir mecanismos para desenvolver suas potencialidades e também reconhecer e respeitar os demais indivíduos que compõem o grupo social. Os programas de computador e a soberania digital possuem enorme destaque em tal processo, posto que o crescimento dos softwares livres no mercado nacional de forma expressiva e a efetiva competição destes programas com os softwares proprietários possibilitaria uma expansão no setor, beneficiando o setor tecnológiconacional.

A cidadania e o reconhecimento são também digitais, uma vez que, no atual contexto da sociedade da informação, a possibilidade de livre acesso às tecnologias e ao desenvolvimento de softwares que propiciem este feito são quesitos fundamentais. Diante disso, é necessário ponderar que os dados da tabela revelam ainda uma dimensão refratária ao software livre, gerando uma defasagem no acesso ao mundo digital por comunidades pobres do Brasil.

Além do mais, no contexto competitivo, há ainda, pelos dados, um obstáculo à disseminação de tais programas livres. A legislação de proteção à concorrência não causa mudanças nesse quadro, sendo utilizada somente para garantir a liberdade de mercado entre os competidores de softwareproprietário.

Infere-se, pois, um reforço nesse tipo de comportamento de mercado pela própria legislação protetiva de direito autoral aplicada aos programas de computador, já que a restrição de acesso ao código-fonte dos softwares proprietários não se reverte de maneira alguma em soberania tecnológica nacional, mas tão somente numa estrutura que assegura a empresas estrangeiras o controle amplo do mercado de softwares brasileiro e a impossibilidade de competição e, consequentemente, de maiores inovações nestesetor.

Esta legislação, em vez de promover um maior acesso ao conhecimento e ao mundo digital, constitui-se como instrumento de garantia de monopólio privado do software. Os dados servem para referendar a análise supramencionada da legislação específica, assim como revelam um processo institucional de alienação de iniciativas nacionais do mercado de software brasileiro, o que reforça o caráter pouco efetivo da legislação hoje vigente no território brasileiro. 
O mercado nacional de softwares representa, desta maneira, muito mais do que um montante de quantias em um relatório econômico, mas a própria oportunidade do âmbito social de ditar seu progresso e buscar sua soberania digital. Representa, pois, a possibilidade de atendimento e de inclusão de cada cidadão nacional pelo desenvolvimento de tecnologias que visem, para além da rentabilidade de indústrias externas, a solucionar problemas e a se adaptar frente às especificidades do contexto brasileiro, haja vista seus setores tão diversificados, como agricultura, educação, indústria, saúde eoutros.

A indústria externa de softwares possui seu papel indiscutível no mercado nacional, mas a partir do momento em que ela predominantemente dita os rumos deste setor tão ímpar acaba por criar uma falha no processo de reconhecimento digital dos indivíduos da comunidade brasileira. Isto, porque no processo de escolha de um software diante do atual cenário sempre haverá um monopólio mercadológico externo e proprietário, de código-fontefechado.

Baseando-se em Bankowski (2008), na busca por uma decisão intermediária e na lógica de tensão entre direito e aspiração, a escolha do governo brasileiro, por meio do Decreto de 29 de outubro de 2003, por adotar os softwares livres pode se constituir medida arrazoada, mas aindainsuficiente.

Razoável por buscar entender as aspirações por detrás da escolha de um tipo de software, por buscar preceitos de independência digital e de benefício do próprio país em seu setor tecnológico. Insuficiente por se tratar apenas de medida isolada, sem o devido acompanhamento de outras searas, como a capacitação e o incentivo aos desenvolvedores nacionais para criarem alternativas tecnológicas por meio de seus softwares e de poderem concorrer em iguais condições com indústrias externas, aquecendo e impulsionando omercado.

A Tabela B demonstra que, de fato, o governo trouxe impactos no setor de softwares livres, aumentando os seus investimentos e sendo o maior consumidor deste tipo de tecnologia. No entanto, torna-se mais uma vez claro que este setor ainda é inexpressivo se comparado ao setor de programas de computador proprietários, de códigos-fonte fechados, revelando a insuficiência da atuação política interventiva do governo federal.

Tal política interventiva demonstra a limitada capacidade das medidas legislativas adotadas no processo de transformação da realidade do mercado de softwares. De tal sorte, a principal constatação é de que a escolha do Governo Federal por utilizar um padrão de software que seja livre se configura como uma mera decisão enquanto consumidor de tais tecnologias e não como uma restrição enquanto regulador de mercado.

Os dados analisados demonstram que o mercado proprietário não se modifica substancialmente pela apoio aos softwares livres, mas permanece com o amplo domínio do dito software proprietário fechado em domínios privados. Desse modo, a decisão do governo brasileiro é incapaz de gerar grau significativo de intervenção no setor econômico. 
Assim sendo, a ação da administração pública de impulsionar os softwares livres em suas instâncias ganha contornos de mera escolha, uma vez que, mesmo gerando algum impacto, não transforma a realidade do setor que é de desequilíbrio mercadológico marcado pela plena dependência tecnológica de corporações externas.

Só haveria de se falar em intervenção econômica e de se discutir sobre seus desdobramentos, se devidos ou não, caso as medidas realizadas fossem capazes de trazer o equilíbrio entre formas proprietárias e livres de código-fonte dos softwares e, assim, transformar o panorama deste mercado. Tais efeitos de equilíbrio e transformação do mercado de software não se efetivam, apesar da legislação vigente, conforme se depreende dos dados da tabela B.

Diante do cenário constatado no Brasil, cabe deduzir que as ações governamentais são capazes de gerar transformações, entretanto apenas se integradas e incorporadas pela comunidade, num regime de cooperação entre iniciativas privadas e públicas.

Resta a dúvida se, caso fosse acompanhada de mais incentivos e investimentos a longo prazo, a implantação de softwares livres poderia se tornar, de fato, uma medida estratégica para impulsionar o desenvolvimento nacional de programas de computador e fomentar o equilíbrio no setor. Por enquanto e por si só, esta medida permanece como um filete de água que é incapaz de mover um "moinho digital": pois este ainda carece de forças para operar a transformação e a evolução do setor de programas de computador.

\section{CONSIDERAÇÕES FINAIS}

Esta pesquisa visou investigar o processo de adoção de softwares livres pela administração pública brasileira. Para tanto, valeu-se de uma análise de conteúdo que versa sobre o mercado de programas de computador, bem como o mercado de softwares livres, da investigação de processos similares em outros governos e dos argumentos utilizados para esta mudança de padrões.

O marco teórico utilizado foi constituído pela confluência dos ideários de viver plenamente o direito, de Bankowski e de luta pelo reconhecimento, de Honneth, que guiaram as conclusões deste estudo.

A metodologia visou o maior esclarecimento possível dos passos adotados e se dividiu em três etapas: o estabelecimento e explanação do marco teórico aplicado; a forma de análise qualitativa de conteúdo direto e indireto sobre o mercado brasileiro de softwares e, por fim; a realização de inferências para compreender o revestimento jurídico dado ao processo de implantação de softwares livres pelo governo.

Verificou-se que é praticamente estanque o domínio de indústrias externas sobre o mercado brasileiro de programas de computador de forma que, mesmo com o crescimento da indústria de softwares livres, quase irrisório foi o aumento de desenvolvedores nacionais. 
Constatou-se que as ações que surgiram desde a implantação da política de adoção da forma livre de software geraram impactos no mercado de open source, contudo são insuficientes para atingir seus objetivos principais. Embora as razões elencadas pelo governo brasileiro para tal escolha se demonstrassem de caráter interventivo na busca por soberania tecnológica ou inovação no setor de programas de computador, os desdobramentos fáticos deste incentivo não acompanharam taisaspirações.

Observou-se, deste modo, que a escolha do Governo Federal por adotar a forma livre de softwares se reveste de uma decisão legítima, contudo meramente mercadológica. É, pois, de baixa significância para o mercado total de softwares, que continua dominado por empresas estrangeiras e não se demonstra como capaz de gerar intervenções estruturais relevantes nomercado.

Por conseguinte, ante todo o constatado, conclui-se que para tornar possível o estado de soberania tecnológica e de reversão de benefícios ao cidadão comum, o mercado de softwares necessita de ações muito mais profundas e que sejam capazes de alterar o status quo estabelecido em prol do equilíbrio entre formas proprietárias e livres.

A centralidade desta temática se deve ao fato de que em tempos de revoluções tecnológicas e informacionais, os softwares se encaixam com colossal importância para o desenvolvimento e independência digitais das nações, sobretudo para um país em desenvolvimento como o Brasil. O impulsionamento da indústria nacional de programas de computador através dos softwares livres e sua consequente competição com as formas proprietárias no mercado perpassam meras melhorias tecnológicas e se convertem para o próprio bem social comum.

Logo, investimentos de qualificação a longo prazo e incentivos ao desenvolvimento de softwares livres podem ser alguns dos caminhos a serem considerados. Entretanto, tais ações excedem a mera adoção da forma livre de software pelo governo e devem ser elaboradas visando corrigir a falha de mercado existente, de modo a propiciar a harmonia entre softwares livres e softwares proprietários fechados. Tal cenário pode parecer longínquo, mas são necessários mais incentivos e cooperações com a comunidade no sentido de prover a autonomia tecnológica tão desejada e, assim, atender plenamente às nuances do mercado brasileiro de programas de computador. 


\title{
FREE SOFTWARE AND GOVERNMENT: A FEEBLE TRIC KLE OF WATER IN THE DIGITAL MILL
}

\begin{abstract}
Investigating the government's choice for promoting open source software initiatives is a complex task that demands a deeper look at the software market situation. Through an analytical and empirical approach, this research aims to further understanding of the elements that make up the software market and classify the major problems present in this realm. The theoretical framework applied is the theories of the struggle for recognition and living lawfully. The underpinning of this research is that the adoption of open source software by the Brazilian Government has not changed the essential character of the market, as the structures that could transform the nature of this scenario are still monopolized by proprietary software companies.
\end{abstract}

Keywords: Struggle for recognition. Living lawfully. Intellectual Property. Open Source Software. SourceCode.

\section{REFERENCIAS}

ABES. Mercado Brasileiro de Software: Panorama e Tendências. Edição 2005. Associação Brasileira das Empresas de Software, disponível em: <http://www.abessoftware.com.br/dados-do-setor/anos-anteriores $>$. Acesso em 02 Dez. 2014.

Mercado Brasileiro de Software: Panorama e Tendências. Edição 2006. Associação Brasileira das Empresas de Software, disponível em: <http://www.abessoftware.com.br/dados-do-setor/anos-anteriores>. Acesso em 02 Dez. 2014.

Mercado Brasileiro de Software: Panorama e Tendências. Edição 2007. Associação Brasileira das Empresas de Software, disponível em: <http://www.abessoftware.com.br/dados-do-setor/anos-anteriores>. Acesso em 02 Dez. 2014.

Mercado Brasileiro de Software: Panorama e Tendências. Edição 2008. Associação Brasileira das Empresas de Software, disponível em: <http://www.abessoftware.com.br/dados-do-setor/anos-anteriores>. Acesso em 02 Dez. 2014.

Mercado Brasileiro de Software: Panorama e Tendências. Edição 2009. Associação Brasileira das Empresas de Software, disponível em: 〈http://www.abessoftware.com.br/dados-do-setor/anos-anteriores>. Acesso em 02 Dez. 2014.

Mercado Brasileiro de Software: Panorama e Tendências. Edição 2010. Associação Brasileira das Empresas de Software, disponível em: <http://www.abessoftware.com.br/dados-do-setor/anos-anteriores>. Acesso em 09 Jan. 2015.

Mercado Brasileiro de Software: Panorama e Tendências. Edição 2011. Associação Brasileira das Empresas de Software, disponível em: <http://www.abessoftware.com.br/dados-do-setor/anos-anteriores>. Acesso em 09 Jan. 2015.

Mercado Brasileiro de Software: Panorama e Tendências. Edição 2012. Associação Brasileira das Empresas de Software, disponível em: <http://www.abessoftware.com.br/dados-do-setor/anos-anteriores>. Acesso em 09 Jan. 2015.

Mercado Brasileiro de Software: Panorama e Tendências. Edição 2013. Associação Brasileira das Empresas de Software, disponível em: <http://www.abessoftware.com.br/dados-do-setor/anos-anteriores>. Acesso em 09 Jan. 2015. 
Mercado Brasileiro de Software: Panorama e Tendências. Edição 2014. Associação Brasileira das Empresas de Software, disponível em: <http://www.abessoftware.com.br/dados-do-setor/anos-anteriores>. Acesso em 10 Jan. 2015.

BABBIE, Earl. The Practice of Social Research. Eleventh Edition . Belmont : Thomson Wadsworth , 2007.

BANKOWSKI, Zenon. Law, Love and Computers. The Edinburgh Law Review. Vol. 1. 1996-1997.

Vivendo Plenamente a Lei. Rio de Janeiro: Elsevier Brasil, 2008. 289p.

BRASIL. Decreto de 29 de Outubro de 2003. Institui Comitês Técnicos do Comitê Executivo do Governo Eletrônico e dá outras providências. Recuperado em 25 de Fev. de 2015, de <http://www.planalto.gov.br/ccivil_03/DNN/2003/Dnn10007.htm>.

CASSON, Tony. RYAN, Patrick S. Open Standards, Open Source Adoption in the Public Sector, and Their Relationship to Microsoft's Market Dominance. In: Standards Edge: Unifier or Divider? Ed.: Sherrie Bolin. Sheridan Books, 2006, p. 87. Disponível em SSRN: http://ssrn.com/abstract=1656616. Acesso em 03 de Mar de 2014.

EPSTEIN, Lee. KING, Gary. Pesquisa empírica em direito [livro eletrônico]: as regras de inferência. São Paulo: Direito GV,2013 (Coleção acadêmica livre) 7 Mb. Título original: The rules of inference. - Vários tradutores.

GUIA LIVRE. Referência de Migração para Software Livre do Governo Federal. Organizado por Grupo de Trabalho Migração para Software Livre. Brasília, 2005. 297 p.: il.

HONNETH, Axel. Luta por Reconhecimento: a gramática moral dos conflitos sociais. São Paulo: Editora 34, $2003.296 \mathrm{p}$.

REDDY, Bernard. EVANS, David S. Government Preferences for Promoting Open-Source Software: A Solution in Search of a Problem. National Economic Research Associates. Maio de 2002. Disponível em SSRN: http://ssrn.com/abstract=313202 or http://dx.doi.org/10.2139/ssrn.313202. Acesso em: 28 Out. 2014.

Trabalhoenviadoem 14deagostode2015.

Aceitoem 12 deoutubrode2015. 